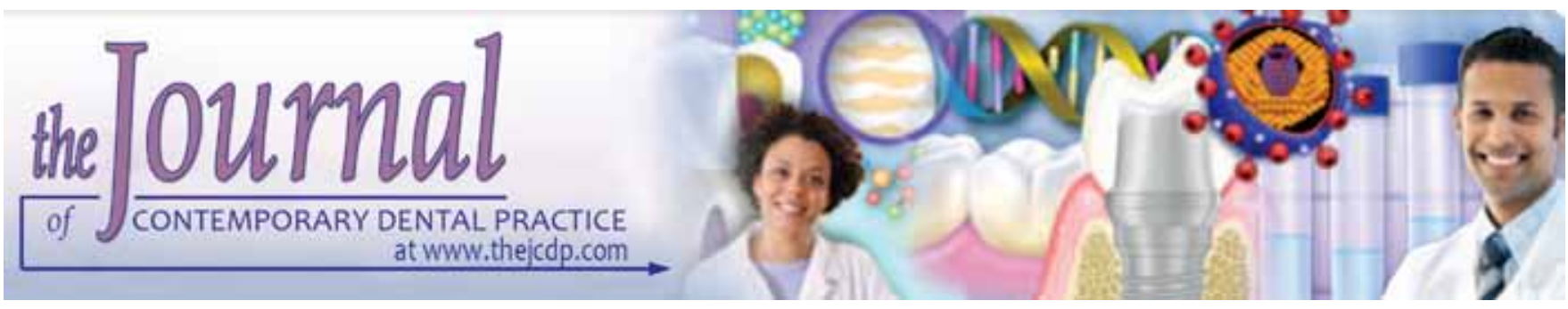

\title{
An Investigation of Blood Hemogram and Estimation of Serum Iron and Protein Levels in Aggressive Periodontitis Patients: A Clinic Biochemical Study
}

\author{
P Krishna Rao, R Vamshidhar Reddy, Sagar Arjun Mapare, Venkat Ratna Nag, K Gowtham, Dimple Arora
}

\section{ABSTRACT}

Aim: The aim of this study is to investigate the blood hemogram and estimation of serum iron and proteins level in aggressive periodontitis patients.

Materials and methods: A total of 85 patients were selected and divided into two groups, 45 patients are with aggressive periodontitis and 40 patients are healthy. Periodontal parameters such as gingival inflammation oral hygiene index, Russell's periodontal index and radiograph were taken. Total $10 \mathrm{ml}$ blood was collected and sent for estimation of blood hemogram protein estimation and serum electrophoresis.

Results: There was statistical significant difference observed in relation to gingival inflammation oral hygiene hemoglobin and total iron binding capacity level between both the groups.

Conclusion: It has been concluded that periodontitis does not induce anemia like state, as the hematological and biochemical parameters were almost equally affected in periodontally healthy and periodontally diseased individuals, but some parameters showed statistical significant difference between the both groups.

Clinical significance: In the present study, the clinical periodontal parameters, red blood cell parameters and serum iron and ferritin levels were compared among control and test groups. It was found that the values of gingival inflammation, oral hygiene and periodontal index, hemoglobulin level and total iron binding protein were statistically significant between the groups. However, the values of erythrocyte count, white blood cell count, serum iron and serum proteins, serum electrophoresis did not show any significant correlation.

Keywords: Aggressive periodontitis, Hemoglobin level, Serum iron, Serum protein, Electrophoresis.

How to cite this article: Rao PK, Reddy RV, Mapare SA, Nag VR, Gowtham K, Arora D. An Investigation of Blood Hemogram and Estimation of Serum Iron and Protein Levels in Aggressive Periodontitis Patients: A Clinic Biochemical Study. J Contemp Dent Pract 2013;14(5):852-857.

Source of support: Nil

Conflict of interest: None declared

\section{INTRODUCTION}

Comprehensive dental care requires dental professionals to assess the general health of their patients and to understand the implications of underlying factors that may impact oral health. One of these underlying factors is the interaction between nutritional status and the immune response to the bacterial challenge in periodontal disease. Alterations in immune response increase the risk and extent of infectious diseases such as periodontal disease. Since the 1970s, the interrelationships of nutrition, immunity and susceptibility to infection have received increasing attention and rigorous study. ${ }^{1,2}$

Patients at risk for inadequate nutritional intakes that compromise the immune response are seen with increasing frequency in private dental practice due to the many advances in medical treatment that allow people (even those with chronic diseases) to live much longer lives. It is important that dental professionals should be able to identify patients at risk for poor nutrition, which may compromise their immune response and place them at higher risk for infection. Deterioration of oral health is highly correlated with deterioration of general health, making it essential that the patient be well nourished in order to respond to the challenge of infectious disease like periodontal diseases. ${ }^{3,4}$

The relationship between nutrition and the periodontium is controversial. Many practitioners are supporters of the concept that nutrition has an influence on the onset, progression of periodontal disease as well as outcome of periodontal therapy. Although dental plaque is the major etiologic factor in periodontal disease, inadequate nutrition may alter the host response to bacterial irritants and render the host more susceptible to establishment or progression of periodontal disease. ${ }^{5}$

Recently, various studies have reported conflicting data for relation between periodontitis and anemia. 
Periodontitis patients have a lower hematocrit, lower numbers of erythrocytes, lower hemoglobin levels and higher erythrocyte sedimentation rates (ESRs). ${ }^{6}$

For thousands of years, blood has been regarded as the ultimate body fluid that could indicate disease process. In the past decade, there has been a renewed interest to study the association of periodontitis and changes in the cellular and molecular components of peripheral blood. For example the relationship of periodontitis with leukocytes, thrombocytes, C-reactive protein (CRP), interleukin (IL)-6, fibrinogen; ESR, Von Willebrand factor and red blood cells has been investigated. ${ }^{7,8}$

Aggressive periodontitis comprises a group of rare, often severe, rapidly progressive forms of periodontitis often characterized by an early age of clinical manifestation and a distinctive tendency for cases to aggregate in families. ${ }^{1,9}$

Aggressive periodontitis describes three diseases formerly classified as early onset periodontitis.

1. Localized aggressive periodontitis (formerly called as localized juvenile periodontitis).

2. Generalized aggressive periodontitis (formerly called as generalized juvenile periodontitis).

3. Rapidly progressive periodontitis.

Aggressive form of periodontal diseases based on the following primary features:

1. Noncontributory medical history

2. Familial aggregation of cases

3. Rapid attachment loss and bone destruction.

Secondary features that are considered by generally but not universally present are:

1. Amount of microbial deposits inconsistent with the severity of periodontal tissue destruction.

2. Elevated proportions of amino acids and in some far east populations, Porphyromonas gingivalis.

3. Phagocyte abnormalities.

4. Hyper-responsive phagocyte, including elevated production of prostaglandin E2 (PGE2) and IL-1 $\beta$ in response to bacterial endotoxins.

5. Progression of attachment loss and bone loss may be self-arresting.

\section{MATERIALS AND METHODS (FIGS 1 TO 3)}

A total of 85 patients were selected from the Department of Periodontology, Government Dental College. The patients were divided into two groups, patient with aggressive periodontitis test group (45 patients) and control group 40 without periodontitis patients. After ethical approval, the purpose and design of the study was verbally explained to the patients and written informed consent was obtained.

Gingival inflammation index (GI), simplified oral hygiene index (OHI-S), Russell's periodontal index (RI)

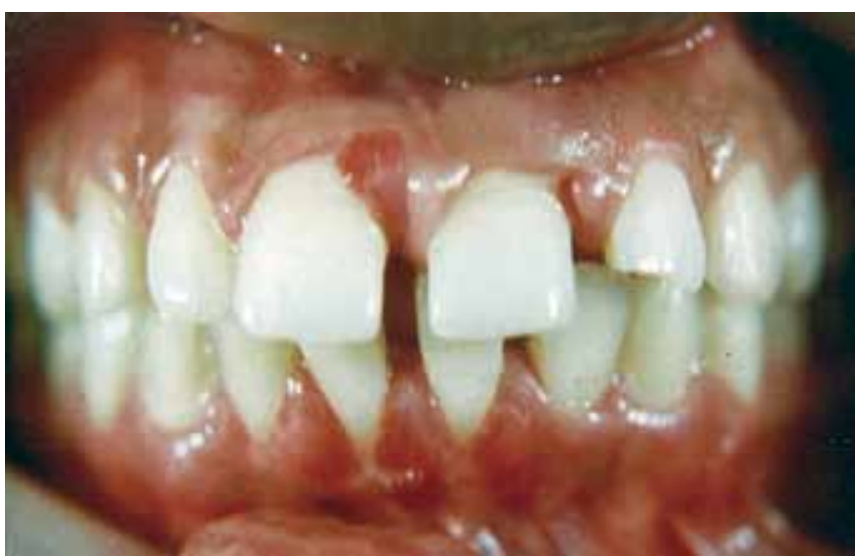

Fig. 1: Aggressive periodontitis patient

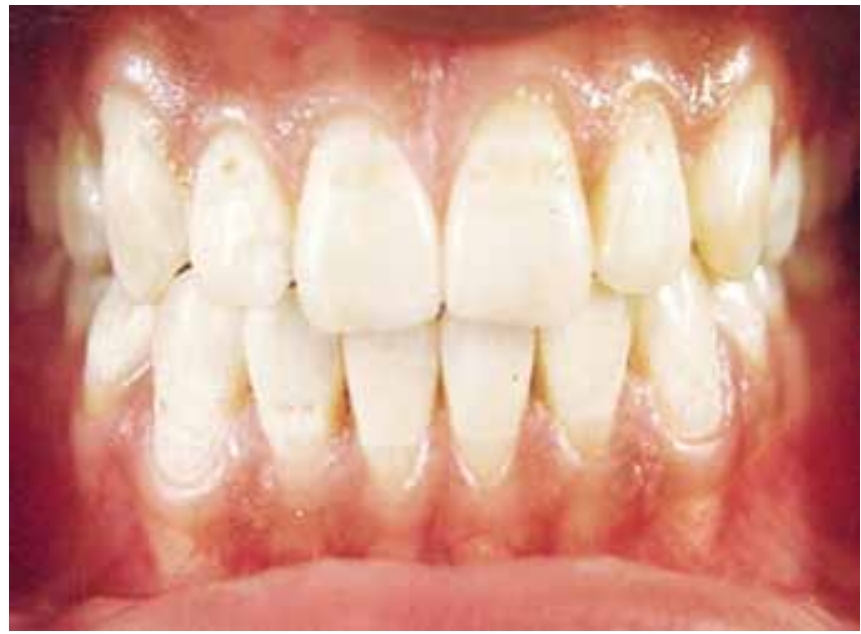

Fig. 2: Healthy patient

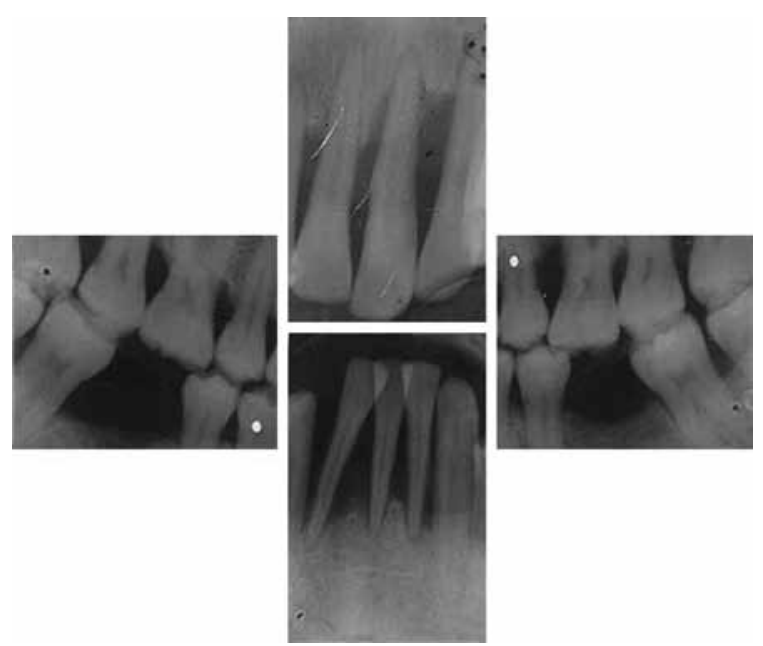

Fig. 3: Full mouth intraoral periapical radiograph showing involvement of molars and incisors

were recorded using a marked periodontal probe. Intraoral periapical radiograph were taken for upper and lower anteriors and bitewing X-ray for posterior teeth.

\section{Blood Analysis}

Under aseptic conditions, $10 \mathrm{ml}$ of venous blood was drawn from antecubital fossa. From $1 \mathrm{ml}$ of blood total 


\begin{tabular}{lccccc}
\multicolumn{2}{l}{ Table 1: Distribution of subjects by gingival inflammation index } \\
\cline { 2 - 3 } $\begin{array}{l}\text { Gingival } \\
\text { inflammation } \\
\text { index }\end{array}$ & \multicolumn{2}{c}{ Experimental } & & \multicolumn{2}{c}{ Control } \\
\cline { 2 - 3 } \cline { 5 - 6 } Mild & 33 & $\%$ & & No. & $\%$ \\
Moderate & 12 & 26.6 & & 24 & 60.0 \\
\hline
\end{tabular}

**The proportion of subjects with mild gingival inflammation index is significantly higher from that of control by small sample proportion 't' test $(p<0.01)$.

\begin{tabular}{|c|c|c|}
\hline $\mathrm{OHI}$ & Experimental $(n=45)$ & Control $(n=40)$ \\
\hline Good & 15.5 & 5.0 \\
\hline Fair & $69.0^{*}$ & 87.5 \\
\hline Poor & 15.5 & 7.5 \\
\hline
\end{tabular}

*The proportion of subjects in experimental group with 'Fair' oral hygiene index is significantly lower than that of control group by small sample proportion ' $t$ ' test $(p<0.05)$

\begin{tabular}{|c|c|c|c|c|}
\hline \multirow[t]{2}{*}{ Clinical condition } & \multicolumn{2}{|c|}{ Experimental } & \multicolumn{2}{|c|}{ Control } \\
\hline & No. & $\%$ & No. & $\%$ \\
\hline $\begin{array}{l}\text { Clinically normal supportive } \\
\text { tissues }\end{array}$ & 0 & 0 & 40 & $100^{* * *}$ \\
\hline Simple gingivitis & 0 & 0 & - & - \\
\hline $\begin{array}{l}\text { Begining destructive } \\
\text { periodontal disease }\end{array}$ & 7 & 15.55 & - & - \\
\hline $\begin{array}{l}\text { Established destructive } \\
\text { periodontal disease }\end{array}$ & 30 & 66.67 & - & - \\
\hline Terminal disease & 8 & 17.78 & - & - \\
\hline
\end{tabular}

*** The proportion of subjects with clinically normal supportive tissues in control group is statistically higher compared to that of experimental group by small sample proportion ' $t$ ' test $(p<0.001)$

\begin{tabular}{lcc}
\multicolumn{3}{l}{ Table 4: Mean values of biochemical estimation in two groups } \\
\hline & Experimental $(n=45)$ & Control $(n=40)$ \\
\hline RBC & $4.2 \pm 0.65^{+}$ & $4.24 \pm 0.46$ \\
WBC & $10,193.8 \pm 1171.67$ & $10,040 \pm 1016.55$ \\
$\mathrm{Hb}(\mathrm{gm})$ & $12.3 \pm 2.88$ & $14.6^{* * *} \pm 2.27$ \\
$\mathrm{Hb}(\%)$ & $77.4 \pm 10.5$ & $82.4^{*} \pm 7.59$ \\
Serum iron & $130.5 \pm 45.99$ & $131.7 \pm 38.7$ \\
TIBC & $488.3 \pm 1.77 .18$ & $512.4 \pm 161.76$ \\
Total protein & $7.34 \pm 1.28$ & $7.2 \pm 0.55$ \\
Serum albumin & $4.61 \pm 0.61$ & $4.6 \pm 0.68$ \\
Serum globulin & $2.93 \pm 0.68$ & $2.6 \pm 0.54$ \\
\hline
\end{tabular}

${ }^{+}$values are mean $\pm \mathrm{SD}$; ${ }^{* * *}$ Mean hemoglobin $(\mathrm{gm} / \mathrm{dl})$ value of control subjects was significantly higher than that of experimental subjects by Student ' $t$ ' test $(p<0.001)$; *Mean hemoglobin (\%) value of control subjects was significantly higher compared to experimental value by student t-test $(p<0.05)$

red blood cell count, white blood cell count, estimation of hemoglobin was done and remaining $9 \mathrm{ml}$ blood was sent for centrifugation to get serum for estimation of total proteins, albumin total iron and total iron binding capacity. The remaining serum was used for studying electrophoresis (Fig. 4) pattern for different proteins motifs.

\begin{tabular}{lccccc}
\multicolumn{5}{r}{ Table 5: Percent distribution of subjects according to } \\
hemoglobin values
\end{tabular}

*** The mean hemoglobin values of subjects in control group was statistically higher than that of subjects in experimental group

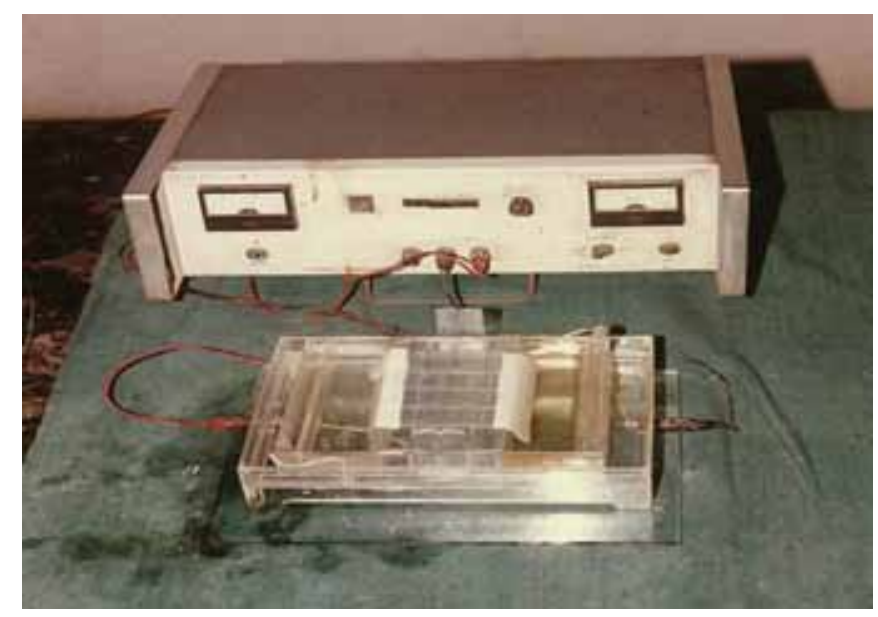

Fig. 4: Electrophoresis apparatus

\section{RESULTS}

Data were analyzed by using statistical analysis.

Gingival inflammation index (Table 1) indicated 73.4\% of aggressive periodontitis and showed mild gingival inflammation and remaining $26.6 \%$ showed moderate inflammation. In comparison between two groups mild gingival inflammation was significantly higher in test group (73.4\%) as compared to control group (40\%) by proportion 't'-test $(\mathrm{p}<0.01)$.

Oral hygiene status (Table 2 ) showed $15.5 \%$ of test group with good oral hygiene and $69 \%$ had fair oral hygiene and $15.5 \%$ had poor oral hygiene and for control group 5, 87.5 and $7.5 \%$ showed good, fair and poor hygiene respectively.

Periodontal index (Table 3), 67\% of the experimental group indicated established destructive periodontal disease and $17.8 \%$ indicated terminal disease and in control group it showed healthy periodontium.

Hemoglobin level (Table 5, Graph 1), it was observed that the mean $\mathrm{Hb}$ in control subjects was statistically higher as compared to test group $(\mathrm{p}<0.001)$.

There was no statistical significant difference in RBC and WBC count serum iron between both the groups.

There was statistical significant difference in total iron binding capacity (TIBC) (Graph 2) between both the groups. The mean for test group was $488.3 \mu \%$ and control was $512.4 \mu \%$ [by Student ' $t$ '-test $(\mathrm{p}<0.05)$ ]. 


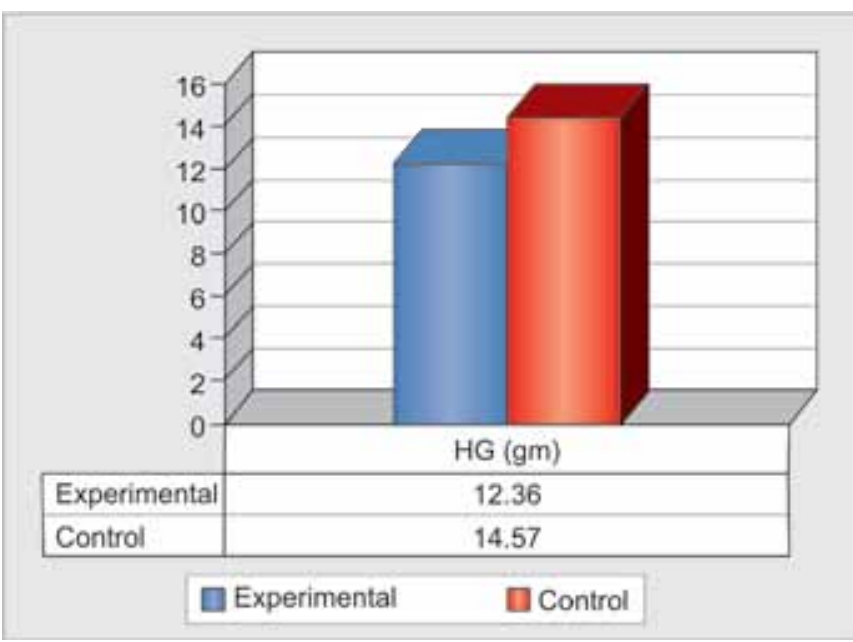

Graph 1: Group-wise comparision of biochemical parameters hemoglobin $(\mathrm{g} / \mathrm{dl})$

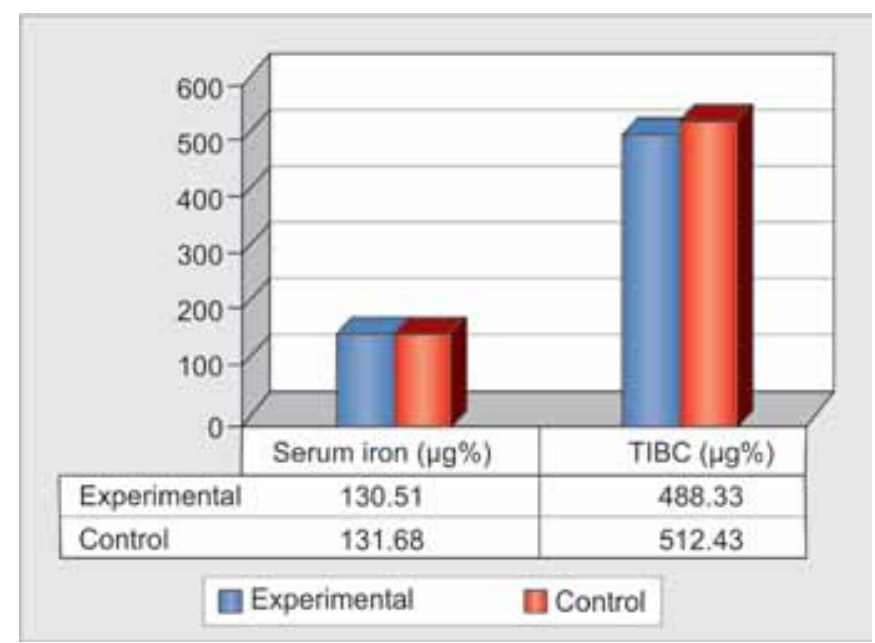

Graph 2: Group-wise comparision of serum iron and TIBC

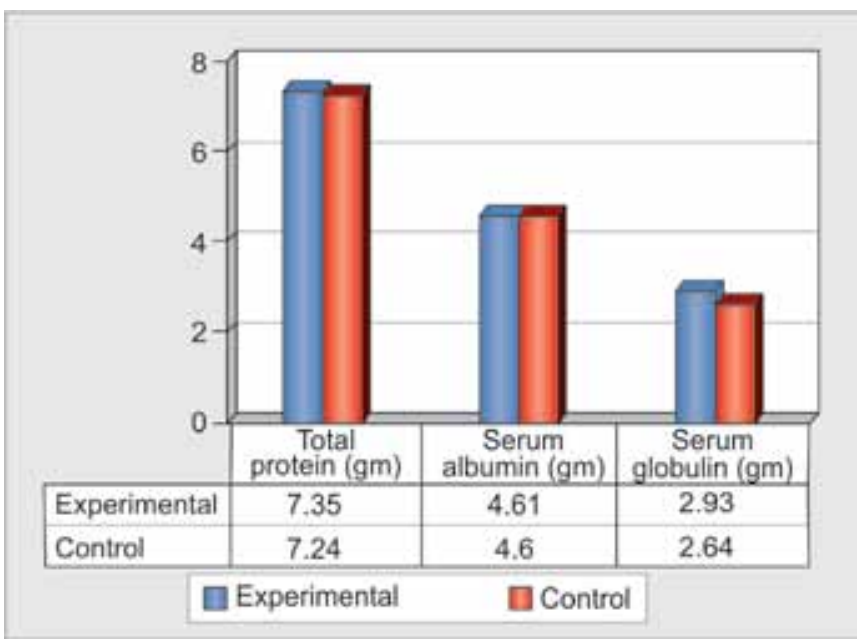

Graph 3: Group-wise comparision of biochemical parameters

There was no statistical significant difference in total proteins albumin, globulin (Table 4 and Graph 3 ) and serum electrophoresis levels (Figs 5 and 6) in both the groups.

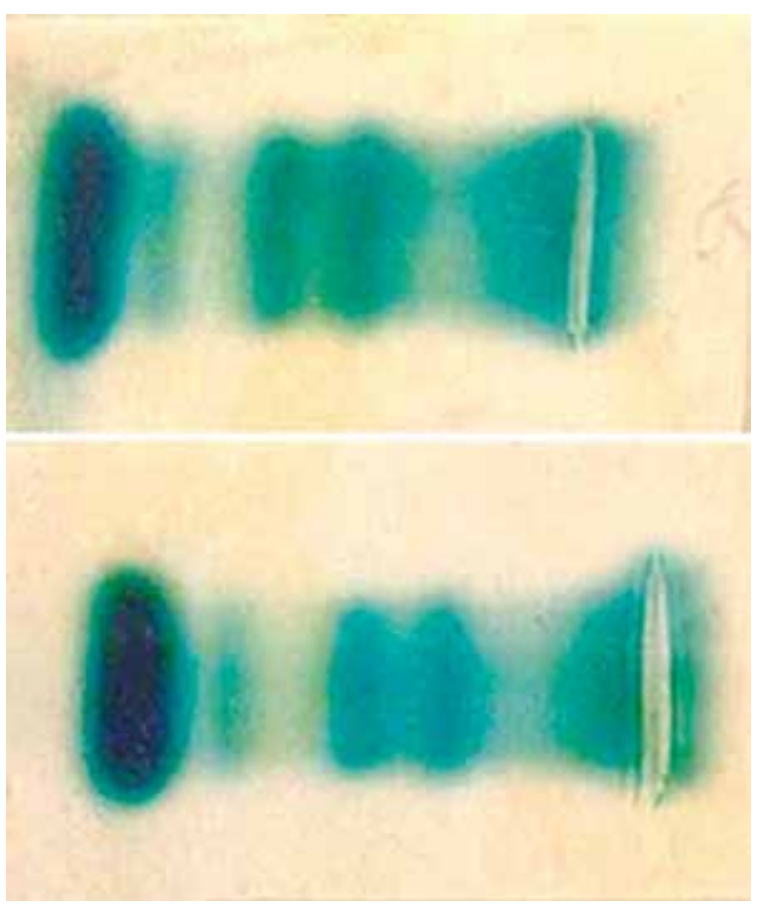

Fig. 5: Electrophoresis pattern of aggressive periodontitis group showing normal pattern

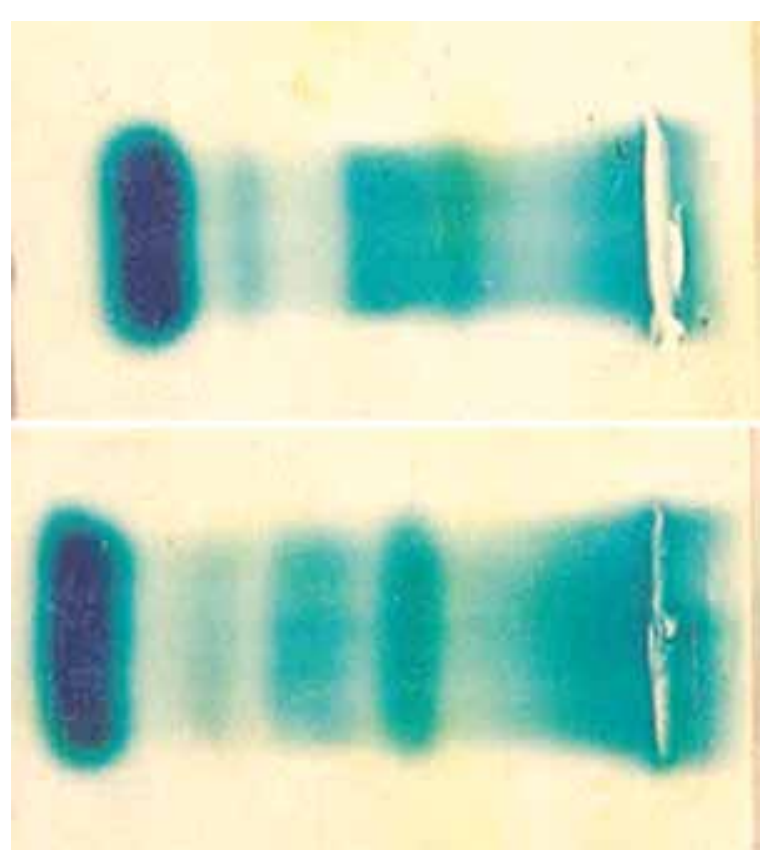

Fig. 6: Electrophoresis pattern of healthy group showing normal pattern

\section{DISCUSSION}

The relation between anemia with infection and chronic systemic disorders has been well established. It has been observed that infection is associated with profound disturbance in iron metabolism and decreased incorporation of iron into hemoglobin gives rise to anemia. There is little importance; very little work seems to have been attempted at the association of periodontitis with this blood disorder. ${ }^{10,11}$ 
In the present study, the clinical periodontal parameters, red blood cell, white blood cell parameters and serum iron, total iron binding protein and serum proteins levels were compared among control and test groups. It was found that the values of gingival inflammation, oral hygiene and periodontal index hemoglobulin level, total iron binding protein were statistically significant between the groups $(p<0.001)$. However, the values of erythrocyte count, white blood cell count, serum iron and serum proteins, serum electrophoresis did not show any significant correlation.

Various studies have tried to evaluate the relationship between periodontitis and hemoglobin. It was found that periodontitis patients have lower hematocrit, lower numbers of erythrocytes, lower hemoglobin levels and higher ESRs when compared to healthy controls. ${ }^{12,13}$

Furthermore, few studies failed to show any association between hemoglobin levels and periodontal status in patients with localized aggressive periodontitis, generalized aggressive periodontitis. ${ }^{14}$

Some studies also did not show any significant correlation between the periodontal index and hematocrit, hemoglobin values or total erythrocyte count and moderate and severe periodontal disease. Similarly, others also observed no significant correlation between periodontal index, periodontal disease index and hemoglobin values. ${ }^{15,16}$

\section{CONCLUSION}

Anemia as reflected by low hemoglobin level in aggressive periodontitis patients is constant finding as was observed and in the present study anemia is not coinciding with low serum or plasma protein level. Further longitudinal studies with larger sample size are needed to investigate the association between hemoglobin levels and different types of periodontitis, and the effect of periodontal treatment on hemoglobin level.

\section{CLINICAL SIGNIFICANCE}

In the present study, the clinical periodontal parameters, red blood cell parameters and serum iron and ferritin levels were compared among control and test groups. It was found that the values of gingival inflammation, oral hygiene and periodontal index, hemoglobulin level, total iron binding protein were statistically significant between the groups; however, the values of erythrocyte count, white blood cell count, serum iron and serum proteins, serum electrophoresis did not show any significant correlation.

\section{REFERENCES}

1. Carranza FA. Influence of systemic diseases on the periodontium. In: Carranza, FA, Newmann MG, editors. Clinical periodontology. 8th ed. Philadelphia: WB Saunders; 1996. p. 185-205.
2. Katz J. Dental correlation nutritional disorders. In: Kaye D, Rose LF, editors. Internal medicine for dentistry. 2nd ed. St Louis: Mosby Company; 1990. p. 978-985.

3. Ebersole JL, Cappelli D. Acute-phase reactants in infections and inflammatory diseases. Periodontol 2000 2000;23:19-49.

4. Loos BG, Craandijk J, Hoek FJ, Wertheim-van Dillen PM, van der Velden U. Elevation of systemic markers related to cardiovascular diseases in the peripheral blood of periodontitis patients. J Periodontol 2000;71(10):1528-1534.

5. Pradeep AR, Sharma A, Arjun Raju P. Anemia of chronic disease and chronic periodontitis: does periodontal therapy have effect on anemic status. J Periodontol 2011;82:388-394.

6. Erdemir EO, Nalcaci R, Caglayan O. Evaluation of systemic markers related to anemia of chronic disease in the peripheral blood of smokers and non-smokers with chronic periodontitis. Eur J Dent 2008;2:102-109.

7. Loos BG. Systemic markers of inflammation in periodontitis. J Periodontol 2005;76(11Suppl):2106-2115.

8. Cohen SG, Glick M. Dental correlation, anemia and deficiency states. In: Kaye D, Rose LF, editors. Internal medicine for dentistry. 2nd ed. St Louis: Mosby Company; 1990. p. 360-361.

9. Christan C, Dietrich T, Hagewald S, Kage A, Bernimoulin JP. White blood cell count in generalized aggressive periodontitis after non-surgical therapy. J Clin Periodontol 2002;29(3):201-206.

10. Gokhale SR, Sumanth S, Padhye AM. Evaluation of blood parameters in patients with chronic periodontitis for signs of anemia. J Periodontol 2010;81:1202-1206.

11. Agarwal N, Kumar VS, Gujjari SA. Effect of periodontal therapy on hemoglobin and erythrocyte levels in chronic generalized periodontitis patients: An interventional study. J Indian Soc Periodontol 2009; 13:6-11.

12. Hutter JW, van der Velden U, Varoufaki A, Huffels RA, Hoek FJ, Loos BG. Lower numbers of erythrocytes and lower levels of hemoglobin in periodontitis patients compared to control subjects. J Clin Periodontol 2001;28(10):93.

13. Thomas B, Ramesh A, Ritesh K. Relationship between periodontitis and erythrocyte count. J Ind Soci Periodontol 2006;10:288-291.

14. Havemose-Poulsen A, Westergaard J, Stoltze K, Skjødt H, Danneskiold-Samsøe B, Locht H, Bendtzen K, Holmstrup P. Periodontal and hematological characteristics associated with aggressive periodontitis, juvenile idiopathic arthritis, and rheumatoid arthritis. J Periodontol 2006;77(2):280-288.

15. Lainson PA, Brady PP, Fraleigh CM. Anemia, a systemic cause of periodontal disease? J Periodontol. 1968;39:35-38.

16. Chawla TN, Kapoor KK, Teotia SPS, Singh N. Anemia and periodontal disease-a correlative study. J Indian Dent Assoc 1971;43:67-78.

\section{ABOUT THE AUTHORS}

\section{P Krishna Rao (Corresponding Author)}

Professor and Head, Department of Periodontics, HSRSM Dental College and Hospital, Hingoli, Maharashtra, India, e-mail: doctorpydi@gmail.com

\section{R Vamshidhar Reddy}

Professor and Head, Department of Orthodontics, HSRSM Dental College and Hospital, Hingoli, Maharashtra, India 


\section{Sagar Arjun Mapare}

Reader, Department of Orthodontics, HSRSM Dental College and Hospital, Hingoli, Maharashtra, India

\section{Venkat Ratna Nag}

Reader, Department of Prosthodontics, SB Patil Dental College, Bidar Karnataka, India

\section{K Gowtham}

Senior Lecturer, Department of Conservative Dentistry and Endodontics Malla Reddy Dental College, Hyderabad, Andhra Pradesh, India

\section{Dimple Arora}

Assistant Professor, Department of Physiology, CM Medical College Durg, Chhattisgarh, India 